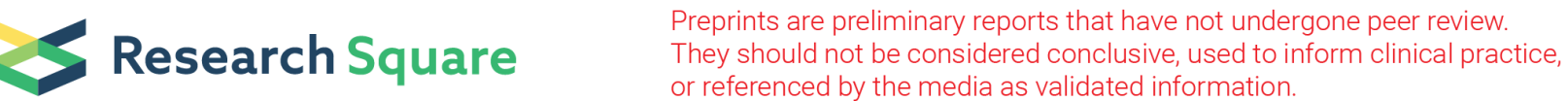

\section{Comparative Analysis of Daily and Hourly Temperature Variability in Association with All- Cause and Cardiorespiratory Mortality in 45 US Cities}

\section{Yong Yu}

Hubei University of Medicine

Siqi Luo

Wuhan University of Science and Technology

\section{Yunquan Zhang}

Wuhan University of Science and Technology https://orcid.org/0000-0002-2618-5088

Linjiong Liu

Wuhan University of Science and Technology

\section{Ke Wang}

Wuhan University of Science and Technology

\section{Le Hong}

Wuhan University of Science and Technology

Qun Wang ( $\nabla$ hbmu@hbmu.edu.cn)

Hubei University of Medicine

\section{Research Article}

Keywords: Temperature variability, Cardiovascular, Respiratory, Mortality risk, Attributable fraction, United States.

Posted Date: July 23rd, 2021

DOl: https://doi.org/10.21203/rs.3.rs-684495/v1

License: (c) (1) This work is licensed under a Creative Commons Attribution 4.0 International License. Read Full License

Version of Record: A version of this preprint was published at Environmental Science and Pollution Research on September 19th, 2021. See the published version at https://doi.org/10.1007/s11356-02116476-9. 


\section{Abstract}

\section{Background}

Temperature variability (TV) has been widely associated with increased mortality risk and burden. Extensive researches have used the standard deviations of several days' daily maximum and minimum temperatures or hourly mean temperatures as daily and hourly $T V$ measures $\left(T V_{\text {daily }}\right.$ and $\left.T V_{\text {hourly }}\right)$. However, comparative analysis of daily and hourly TV related to cardiorespiratory mortality is still limited.

\section{Methods}

We collected daily mortality and meteorological data in 45 US metropolises, 1987-2000. A three-stage analyses were adopted to investigate $T V$-mortality associations using $T V_{\text {daily }}$ and $T V_{\text {hourly }}$ as exposure metrics. We first applied a time-series quasi-Poisson regression to estimate location-specific TV-mortality relationship, which were then pooled using random-effects meta-analysis with maximum likelihood estimation (MLE). We additionally calculated attributable fractions as a reflection of total mortality burden associated with TV. Stratified analyses by age were also performed to identify the susceptible group to TV-related risk.

\section{Results}

There were a total of 15.4 million all-cause deaths, of which 6.1 million were from cardiovascular and 1.2 million were from respiratory causes. Per $1{ }^{\circ} \mathrm{C}$ increase in $\mathrm{TV}_{\text {daily }}$ and $\mathrm{TV}_{\text {hourly }}$ was associated with an increase of $0.53 \%$ ( $95 \%$ confidence interval: $0.31-0.76 \%)$ and $0.52 \%(0.26-0.79 \%)$ in cardiovascular mortality risks, $0.62 \%(0.26-0.98 \%)$ and $0.53 \%(0.13-0.94 \%)$ in respiratory mortality risks. Estimations of cardiovascular attributable fractions for $\mathrm{TV}_{\text {daily }}$ and $\mathrm{TV}_{\text {hourly }}$ were $2.43 \%(1.42-3.43 \%)$ vs $1.63 \%$ (0.82$2.43 \%)$, whereas respiratory attributable fractions were $3.07 \%(1.11-4.99 \%)$ vs $1.89 \%(0.43-3.34 \%)$. Both daily and hourly indexes showed approximately linear relationships with different mortality categories and similar lag patterns, but greater fractions were estimated using $\mathrm{TV}_{\text {daily }}$ than those using $\mathrm{TV}_{\text {hourly. }}$. People over 75 years old were relatively more vulnerable to TV-induced risks of mortality.

\section{Conclusions}

Both $\mathrm{TV}_{\text {daily }}$ and $\mathrm{TV}_{\text {hourly }}$ significantly increased all-cause and cardiorespiratory mortality risks and burden. Daily TV metrics resembled hourly in risk effects, whilst greater mortality burden was found in $\mathrm{TV}_{\text {daily }}$ than $\mathrm{TV}_{\text {hourly. }}$. Our findings may add significance to $\mathrm{TV}$-mortality research and help to promote optimal health management strategies to better mitigate TV-related health effect.

\section{Introduction}

Climate change has become a leading concern among global communities over the past decades (Gasparrini et al. 2017; Song et al. 2017). Temperature extremes are closely related to increases in 
mortality among extensive epidemiologic studies at national and regional scales. Global Burden of Disease (GBD) 2019 has incorporated high and low temperatures into its environmental risk factors separately (Cheng et al. 2019a; Ye et al. 2012), emphasizing the essentiality of mitigating the health impact of extreme temperature in the context of global warming.

Except for high and low temperatures, temperature variability (TV) has also been widely regarded as a potential trigger for excess mortality risks (ERR). Globally the association between TV and all-cause or cause-specific mortality has been well-documented in the scientific literature using different analytic strategies and temperature indexes (Chen et al. 2018). Most studies just adopted either intraday (e.g. diurnal temperature range, DTR) (Lee et al. 2020) or interday (e.g. temperature change between neighboring days, TCN) (Zhan et al. 2017) temperature indexes to assess the impacts, which may cause potential bias to the results (Vicedo-Cabrera et al. 2016). And putting two indicators into the model at the same time may cause strong collinearity especially when considering the lag effect (Guo et al. 2016; Hu et al. 2019).

$\mathrm{TV}_{\text {daily }}$ and $\mathrm{TV}_{\text {hourly, }}$ calculated by the standard deviations of several days' daily maximum and minimum temperatures or hourly mean temperatures, have been applied separately in studies in different countries and regions, including Australia (Cheng et al. 2017), China (Ban et al. 2017), England and Wales (Zhang et al. 2018), Brazil (Zhao et al. 2018), Japan (Ma et al. 2019), etc. Either of these two indexes can

effectively promote awareness of the health effect due to temperature changes, while $\mathrm{TV}_{\text {hourly }}$ is considered better to capture the temperature fluctuations at a finer scale (Cheng et al. 2017).

Nevertheless, sporadic researches have focused on the estimated difference between these two metrics.

Hence, our previous publication has compared the effects of these two TV metrics related to all-cause mortality in China, US and UK (Zhang et al. 2019a), where $\mathrm{TV}_{\text {daily }}$ and $\mathrm{TV}_{\text {hourly }}$ are found to significantly increase all-cause mortality risk and burden. However, comparative analysis of $\mathrm{TV}_{\text {daily }}$ and $\mathrm{TV}_{\text {hourly }}$ associated with cause-specific mortality has not been reported. In this study, we aimed to further explore cardiorespiratory mortality risks and attributable fractions (AF) related to TV, also comparing the results of these two metrics ( $T V_{\text {daily }}$ and $T V_{\text {hourly }}$ ) to see the differences.

\section{Materials And Methods}

\section{Data collection}

Daily mortality and meteorological data during 1987-2000 were derived from the National Morbidity, Mortality and Air pollution Study (NMMAPS), leading by the School of Public Health, Hopkins University. We extracted 45 metropolises in seven regions from 108 American cities contained in the dataset (Fig. 1): North West (7), Upper Midwest (4), Industrial Midwest (10), North East (7), Southern California (3), South East (9), and South West (5). Mortality data for all ages were classified into the following five categories: all-cause, non-accidental, cardiovascular, respiratory and cardiorespiratory disease. Daily meteorological data covered daily mean temperature $\left({ }^{\circ} \mathrm{C}\right)$, maximum temperature $\left({ }^{\circ} \mathrm{C}\right)$, minimum temperature $\left({ }^{\circ} \mathrm{C}\right)$ and 
daily average relative humidity (\%). More details could be seen in previous publications (Peng et al. 2005).

Hourly temperatures were extracted for 45 US metropolises during the same period through Local Climatological Data (LCD) of National Centers for Environmental Information

(https://www.ncdc.noaa.gov/cdo-web/datatools/lcd/). LCD consists of hourly, daily, and monthly summaries for approximately 1600 US locations, which provides users worldwide the historical weather data at airports.

\section{Calculation of temperature variability}

In this study, we used $\mathrm{TV}_{\text {daily }}$ and $\mathrm{TV}_{\text {hourly }}$ to assess short-term $\mathrm{TV}$. $\mathrm{TV}_{\text {daily }}$ was calculated by the standard deviation (SD) of daily minimum and maximum temperatures (Guo et al. 2016), whilst $T V_{\text {hourly }}$ was captured from the SD of hourly temperatures during the exposure days (Cheng et al. 2017). These two metrics could overcome strong collinearity when putting intraday and interday TV into the same model and account for the delay effects of temperature variation at the same time (Guo et al. 2016).

Additionally, TV at lag 0-1 days was calculated by the SD of temperatures on the same day and one day before. We conducted separate analyses for TV during different exposure days from lag $0-1$ days to lag 0-10 days, and selected lag $0-7$ days as our main concern.

\section{Statistical analysis}

Statistical analysis was done in three stages. In the first stage, we applied a time-series quasi-Poisson regression to fit generalized linear models for temperature-mortality associations (Bhaskaran et al. 2013; Gasparrini et al. 2015). This model was based on the definition of a crossbasis function combining exposure-response and lagresponse associations (Gasparrini and Leone 2014; Yang et al. 2015). To adjust for the potential non-linear effects of daily mean temperature related to mortality, we adopted a cross-basis function with up to 21 lag days for daily mean temperature, using a natural cubic spline (NCS) with 4 degrees of freedom (df) for both temperature and lag days (Guo et al. 2016; Zhao et al. 2018). Besides, we modeled the exposure-response curve with a quadratic B-spline with three internal knots placed at the 10th, 75th, and 90th to speculate city-specific temperature distributions, and three internal knots were placed at equally spaced values on the log scale to measure the lag-response association (Guo et al. 2014). A few important covariates (Gasparrini and Leone 2014) were also adjusted in the model, which included: a NCS of time with $7 \mathrm{df}$ per year to exclude long-term and seasonal trends; a NCS of $3 \mathrm{df}$ for a potential confounder of relative humidity; and indicator variable, day of the week (DOW), controlling for variations within a week.

In the second stage, city-specific estimates were pooled using random-effects meta-analysis with maximum likelihood estimation (MLE) (Viechtbauer 2010) for different causes of death and exposure metrics ( $T V_{\text {daily }}$ and $\left.T V_{\text {hourly }}\right)$. City-specific and pooled estimates of TV effects on all-cause and causespecific mortality were reported as ERR (\%, with 95\% confidence interval [CI]) associated with per $1^{\circ} \mathrm{C}$ increase in $\mathrm{TV}_{\text {daily }}$ or $\mathrm{TV}_{\text {hourly }}$ along different exposure days. 
In the third stage, we used the ERR estimates derived from the second stage to calculate attributable number of deaths $(A D)$ caused by TV on each day, then summed up ADs on each day during the whole series to get the total attributable deaths (Gasparrini et al. 2015; Zhang et al. 2019a). AF values were consequently provided by the ratios of total $A D$ to the corresponding total number of observed deaths. Finally, we stratified all these analyses by three age groups ( $0-64$ years; $65-74$ years; 75 years and above).

\section{Sensitivity analysis}

To assess the robustness of the results, we conducted sensitivity analyses by changing: $\mathrm{df}$ for time trend (68 per year), the maximum lag of temperature (14 days and 28 days), three internal knots were placed to 25th, 50th ,75th as well.

All the analyses were performed in R software version 4.0.3 (R Foundation for Statistical Computing, Vienna, Austria). The "dlnm" package was used for the first-stage distributed lag nonlinear model (Gasparrini 2011), and the "mvmeta" package was used to fit the meta-analysis in the second stage (Gasparrini and Armstrong 2013). A two-sided $p$ value of less than 0.05 was considered statistically significant.

\section{Results}

\section{Descriptive statistics}

Table 1 summarizes descriptive statistics of daily mean number of deaths and weather conditions during the study period in 10 representative cities (complete form could be seen in Table S1). A total of $15,421,862$ deaths were recorded in the whole study period, of which 6.1 million were from cardiovascular causes and 1.2 million were from respiratory causes. Daily mean number of total deaths ranged from 2.3 (Kansas City, KS, 0-12) to 77.7 (Los Angeles, 14-280). Due to large heterogeneity in population size, the number of daily deaths in Chicago and Los Angeles was obviously greater than those of smaller cities. Regardless of the city, deaths due to respiratory diseases accounted for a relatively low proportion (4.3$11.4 \%$ ) of total deaths (Table S2). Average temperatures varied substantially across locations, ranging from $8.8^{\circ} \mathrm{C}$ (Minneapolis/St. Paul) to $26.5^{\circ} \mathrm{C}$ (Phoenix). Additionally, large differences between $\mathrm{TV}_{\text {hourly }}$ and $\mathrm{TV}_{\text {daily }}$ were found in these 45 metropolises, with location-specific averages of $2.4-5.9^{\circ} \mathrm{C}$ for $\mathrm{TV}_{\text {hourly }}$ (Fig. 1) and $3.7-10.1^{\circ} \mathrm{C}$ for $\mathrm{TV}_{\text {daily }}$ (Fig. S1). 
Table 1

Descriptive statistics (mean and range) of daily mortality, mean temperature, relative humidity and temperature variability (daily and hourly) in 10 selected cities.

\begin{tabular}{|c|c|c|c|c|c|}
\hline City & $\begin{array}{l}\text { Daily number of } \\
\text { deaths }\end{array}$ & $\begin{array}{l}\text { Temperature } \\
\left({ }^{\circ} \mathrm{C}\right)\end{array}$ & $\begin{array}{l}\text { Humidity } \\
(\%)\end{array}$ & TV & $\mathrm{TV}_{\text {daily }}$ \\
\hline Albuquerque & $5.3(0-23)$ & $\begin{array}{l}15.8(-11.9 \text { to } \\
36.3)\end{array}$ & $\begin{array}{l}37.2(4.4- \\
98.0)\end{array}$ & $\begin{array}{l}5.1(2.5- \\
8.9)\end{array}$ & $\begin{array}{l}7.6(3.9- \\
11.8)\end{array}$ \\
\hline Chicago & $60.0(8-434)$ & $\begin{array}{l}10.5(-25.9 \text { to } \\
34.9)\end{array}$ & $\begin{array}{l}69.2(25.6- \\
100)\end{array}$ & $\begin{array}{l}4.8(1.5- \\
12.5)\end{array}$ & $\begin{array}{l}6.5(1.7- \\
13.0)\end{array}$ \\
\hline $\begin{array}{l}\text { Colorado } \\
\text { Springs }\end{array}$ & $3.5(0-17)$ & $\begin{array}{l}9.6(-26.9 \text { to } \\
29.6)\end{array}$ & $\begin{array}{l}52.6(7.4- \\
100)\end{array}$ & $\begin{array}{l}5.9(1.9- \\
14.1)\end{array}$ & $\begin{array}{l}8.3(3.3- \\
16.0)\end{array}$ \\
\hline Kansas City, KS & $2.3(0-12)$ & $\begin{array}{l}13.9(-23.7 \text { to } \\
35.8)\end{array}$ & $\begin{array}{l}62.9(16.5- \\
100)\end{array}$ & $\begin{array}{l}5.2(1.6- \\
12.9)\end{array}$ & $\begin{array}{l}8.4(2.5- \\
15.9)\end{array}$ \\
\hline Los Angeles & $77.3(14-280)$ & $\begin{array}{l}17.5 \text { (5.4 to } \\
30.7)\end{array}$ & $\begin{array}{l}71.6(9.5- \\
100)\end{array}$ & $\begin{array}{l}2.6(1.0- \\
6.3)\end{array}$ & $\begin{array}{l}5.8(2.2- \\
9.9)\end{array}$ \\
\hline $\begin{array}{l}\text { Minneapolis/St. } \\
\text { Paul }\end{array}$ & $14.5(0-57)$ & $\begin{array}{l}8.8(-30.0 \text { to } \\
35.5)\end{array}$ & $\begin{array}{l}64.6(17.0- \\
100)\end{array}$ & $\begin{array}{l}4.8(1.0- \\
13.4)\end{array}$ & $\begin{array}{l}6.5(1.2- \\
14.3)\end{array}$ \\
\hline New Orleans & $6.4(0-27)$ & $\begin{array}{l}20.6(-7.5 \text { to } \\
32.5)\end{array}$ & $\begin{array}{l}75.2(27.8- \\
100)\end{array}$ & $\begin{array}{l}4.1(1.4- \\
10.1)\end{array}$ & $\begin{array}{l}5.8(2.6- \\
11.3)\end{array}$ \\
\hline Phoenix & $23.3(1-94)$ & $\begin{array}{l}26.5 \text { (4.2 to } \\
46.2)\end{array}$ & $\begin{array}{l}28.9(5.5- \\
96.4)\end{array}$ & $\begin{array}{l}4.7(2.3- \\
8.1)\end{array}$ & $\begin{array}{l}7.0(3.5- \\
10.1)\end{array}$ \\
\hline San Diego & $22.7(1-91)$ & $\begin{array}{l}17.6 \text { (7.7 to } \\
29.7)\end{array}$ & $\begin{array}{l}73.8(11.9- \\
100)\end{array}$ & $\begin{array}{l}2.4(0.9- \\
6.1)\end{array}$ & $\begin{array}{l}3.8(1.5- \\
7.9)\end{array}$ \\
\hline Stockton & $5.2(0-23)$ & $\begin{array}{l}18.4(-2.6 \text { to } \\
35.7)\end{array}$ & $\begin{array}{l}54.9(17.0- \\
100)\end{array}$ & $\begin{array}{l}5.0(1.0- \\
8.3)\end{array}$ & $\begin{array}{l}10.1(3.8- \\
15.3)\end{array}$ \\
\hline
\end{tabular}

\section{TV-mortality associations}

Figure 2 estimates hourly TV-related ERR from different mortality categories at lag $0-7$ days in each location (results for daily TV not shown). Magnitudes of ERR estimates varied greatly across cities, for instance, the increase of cardiorespiratory mortality risks ranged from $0.85 \%(95 \% \mathrm{Cl}: 0.09-1.62 \%)$ in Cleveland to $3.72 \%(1.55-5.93 \%)$ in Los Angeles. After pooling city-specific risk estimates, $1^{\circ} \mathrm{C}$ rise in TV at lag $0-7$ days was associated with $0.52 \%(0.26-0.79 \%)$ and $0.53 \%(0.13-0.94 \%)$ increase in cardiovascular and respiratory mortality, respectively. As for $\mathrm{TV}_{\text {daily, }}$, corresponding increases were $0.53 \%$ $(0.31-0.76 \%)$ and $0.62 \%(0.26-0.98 \%)$ (Table 2). Pooled results indicated that short-term exposure to large TV would increase the mortality risks in all five mortality categories, while respiratory mortality tended to be most affected. Old people, particularly the elderly over 75, exhibited higher risk compared to younger groups. 
Table 2

Estimated excess mortality risks and attributable fractions (\%, $95 \% \mathrm{Cls})$ in $\mathrm{TV}_{\text {daily }}$ and $\mathrm{TV}_{\text {hourly }}$ at lag $0-7$ days.

\begin{tabular}{|lllll|}
\hline & ERR (\%, 95\%Cl) & \multicolumn{3}{l|}{ AF (\%, 95\%Cl) } \\
\cline { 2 - 5 } & $\mathrm{TV}_{\text {daily }}$ & $\mathrm{TV}_{\text {hourly }}$ & $\mathrm{TV}_{\text {daily }}$ & $\mathrm{TV}_{\text {hourly }}$ \\
\hline Total & $0.55(0.41-0.70)$ & $0.51(0.35-0.66)$ & $2.55(1.94-3.15)$ & $1.65(1.14-2.15)$ \\
\hline Cause & & & & \\
\hline Non-accidental & $0.53(0.38-0.68)$ & $0.49(0.33-0.65)$ & $2.41(1.77-3.05)$ & $1.57(1.05-2.08)$ \\
\hline Cardiorespiratory & $0.55(0.35-0.75)$ & $0.52(0.29-0.75)$ & $2.55(1.67-3.42)$ & $1.67(0.97-2.37)$ \\
\hline Cardiovascular & $0.53(0.31-0.76)$ & $0.52(0.26-0.79)$ & $2.43(1.42-3.43)$ & $1.63(0.82-2.43)$ \\
\hline Respiratory & $0.62(0.26-0.98)$ & $0.53(0.13-0.94)$ & $3.07(1.11-4.99)$ & $1.89(0.43-3.34)$ \\
\hline Age & & & & \\
\hline $0-64$ & $0.38(0.19-0.57)$ & $0.30(0.09-0.52)$ & $2.55(1.94-3.16)$ & $1.64(1.14-2.15)$ \\
\hline $65-74$ & $0.46(0.20-0.72)$ & $0.45(0.15-0.74)$ & $2.57(1.95-3.18)$ & $1.66(1.15-2.17)$ \\
\hline$\geq 75$ & $0.67(0.48-0.89)$ & $0.64(0.40-0.88)$ & $2.54(1.93-3.14)$ & $1.64(1.14-2.14)$ \\
\hline
\end{tabular}

Figure 3 presents the exposure-response curves of cause-specific mortality related to hourly and daily TV exposure metrics. Due to the rare deaths from respiratory diseases, the association between respiratory mortality and TV showed to-some-extent uncertainty. In general, the curves reveal approximately linear TV-mortality relationships in the selected categories, identifying no significant differences between two $T V$ metrics. In all the five mortality categories, effect estimates of $T V_{\text {daily }}$ and $T V_{\text {hourly }}$ along various exposure days were generally comparable and similar lag patterns of TV effects were consistently observed (Figs. 4 \& S2). Overall, mortality risks generally increased from $0-1$ days to $0-7$ days and tended to be stable when the number of exposure days was longer than 8 (i.e., $0-7$ ) days.

\section{Mortality fraction attributable to TV}

Estimates of attributable fractions were the lowest for non-accidental mortality ( $\mathrm{TV}_{\text {daily }}: 2.41 \%, 1.77-$ $3.05 \%$; $\left.\mathrm{TV}_{\text {hourly }}: 1.57 \%, 1.05-2.08 \%\right)$ and the highest for respiratory mortality ( $\mathrm{TV}_{\text {daily }}: 3.07 \%, 1.11-4.99 \%$; $\operatorname{TV}_{\text {hourly }}: 1.89 \%, 0.43-3.34 \%$ ) (Table 2). Remarkably, greater fractions were estimated using $\operatorname{TV}_{\text {daily }}$ than those using $\mathrm{TV}_{\text {hourly }}$. For all mortality categories, the fractions generally increased with the number of exposure days (Table S3). Smaller fractions among people over 75 at lag 0-7 days were found in all the causes of death, while the fractions of respiratory mortality were evidently larger than other causes (Table S4).

\section{Sensitivity analyses}


Sensitivity analyses were performed by controlling df for calendar time, maximum lag and internal knots (Table S5). Estimation on TV-related mortality risk and attributable fractions were insensitive when separately modifying df for calendar time ( 6 and 8 per year), internal knots (25th, 50th, 75th ), and maximum lag of temperature ( 14 days and 28 days). All sensitivity analyses yielded similar estimates as our main analyses. In general, our sensitivity analyses suggested that our results were not dependent on modeling assumptions.

\section{Discussion}

To the best of our knowledge, this is the first study to compare the short-term effects of daily and hourly TV metrics related to cardiorespiratory mortality. Based on 15.4 million deaths, our multi-city analyses showed that both $\mathrm{TV}_{\text {daily }}$ and $\mathrm{TV}_{\text {hourly }}$ were significantly associated with the increase of all-cause and cardiorespiratory mortality, with higher risks observed in the elderly and larger attributable fractions were estimated using $\mathrm{TV}_{\text {daily. }}$

Given no unified definition of TV up to date, DTR and TCN are widely used to represent TV to assess the associations with health outcomes (Li et al. 2021; Lim et al. 2015; Zhan et al. 2017). By contrast, TV $_{\text {daily }}$ and $\mathrm{TV}_{\text {hourly }}$ can better capture the variation of temperature over a short period of time. Relying on very few temperature records (maximum and minimum), the assessed results based on $\mathrm{TV}_{\text {daily }}$ are only an inaccurate assessment of the relationship between TV and mortality. In other words, the standard deviations calculated by the small-scale temperature (i.e., hourly temperatures) provide sufficient data to better capture the fluctuation of temperature within a day. Despite similar TV-mortality patterns between $\mathrm{TV}_{\text {daily }}$ and $\mathrm{TV}_{\text {hourly }}$ were observed in our studies, the potential overestimates were notable in attributable fractions when using $\mathrm{TV}_{\text {daily. }}$. These findings were in line with two comparative analyses (Zhan et al. 2020; Zhang et al. 2019a), both of which argued the priority of TV $_{\text {hourly }}$ in studies investigating TVmortality associations.

In this study, a $1^{\circ} \mathrm{C}$ rise in TV at lag $0-7$ days was associated with an increase of $0.55 \%$ ( $\mathrm{TV}_{\text {daily, }}, 95 \% \mathrm{Cl}$ : $0.41-0.70 \%)$ and $0.51 \%$ ( $\mathrm{TV}_{\text {hourly, }} 0.35-0.66 \%$ ) in all-cause mortality. A generally greater risk of $0.9 \%$ (0.82-0.98\%) for all-cause deaths was derived from a nationwide study in Japan using TV $_{\text {daily }}$ (Ma et al. 2019), while a study in England and Wales experienced twice higher risk (1.13\% [0.88-1.39]) (Zhang et al. 2018). Focused on urban areas, $\mathrm{TV}_{\text {hourly }}$-associated increase in this study was comparable to $0.5 \%$ (0.3$0.7 \%$ ) increase from the five most populous Australian cities (Cheng et al. 2019b). We also estimated an increase of $0.53 \%\left(\mathrm{TV}_{\text {daily, }} 0.31-0.76 \%\right)$ and $0.52 \%\left(\mathrm{TV}_{\text {hourly, }}, 0.26-0.79 \%\right)$ in cardiovascular mortality and $0.62 \%\left(\mathrm{TV}_{\text {daily }}, 0.26-0.98 \%\right)$ and $0.53 \%\left(\mathrm{TV}_{\text {hourly }}, 0.13-0.94 \%\right)$ in respiratory mortality with per $1^{\circ} \mathrm{C}$ rise in TV at lag 0-7 days. No study has ever estimated $\mathrm{TV}_{\text {hourly }}$-related cardiorespiratory mortality, whilst stronger $\mathrm{TV}_{\text {daily }}$-mortality effect of $0.65 \%(0.24-1.05 \%)$ and $0.98 \%(0.57-1.39 \%)$ for cardiovascular and respiratory deaths have been reported from a previous study in 31 major Chinese cities (Yang et al. 2018). Yet the increase of respiratory mortality risk was larger than that of other causes of death, which was similar to our findings. The effect magnitude conducted in various countries and regions was quite 
different, and this spatial and temporal inequality was also documented in preceding multi-country studies (Guo et al. 2016).

Though plenty of epidemiological studies focus on TV-mortality relationships, mechanisms behind health effects of TV-related cardiorespiratory mortality have not yet been understood. Numerous pathophysiological responses and mild inflammation associated with temperatures are postulated to be responsible for the increase in cardiovascular and respiratory diseases (Gasparrini et al. 2015; Graudenz et al. 2006). Sudden variations of temperature within several days exceed the capacity of thermoregulation, causing inflammatory nasal responses and immune system depression (Lim et al. 2015) and the changes in blood pressure, blood viscosity and coagulability (Martinez-Nicolas et al. 2015). These alterations may trigger cardiovascular and respiratory events. In accordance with previous publications, our stratified analysis observed people over 75 years old were at greater risks related to large TV, suggesting higher vulnerability to temperature changes (Hu et al. 2019; Zhang et al. 2019b). In the context of global population ageing (Lee et al. 2019; Yang et al. 2021), cause- and group-specific prevention strategies should be considered to enhance populations' temperature adaptability, especially in elderly people.

Our study had some notable strengths. Compared to daily TV, hourly TV had a superior description of temperature variations. Hourly temperature records can better capture the temporal changes in temperature, which may decline the potential bias. Moreover, we investigated cardiovascular and respiratory mortality related to TV, which could further the understanding of cause-specific TV-mortality associations. There are also some limitations of the present study. First, ambient air pollutants were not taken into account due to data unavailability for some cities, and the previous analyses did not find a significant contribution of air pollutants when assessing the relationship between temperature and health (Lim et al. 2015). Second, this study could not be considered nationally representative because we selected 45 megacities in urban areas to analysis and did not cover rural regions. Third, the small sample size of respiratory deaths might introduce uncertainty when assessing TV-mortality association, with respiratory results exhibiting unstable linear relationships and relatively large errors. Moreover, we did not classify cardiovascular and respiratory disease into a finer scale, which further investigation should concentrate on.

\section{Conclusions}

In summary, our study added evidence to comparative analyses of short-term daily and hourly TV in association with cardiorespiratory mortality. Short-term exposure to large $\mathrm{TV}_{\text {daily }}$ or $\mathrm{TV}_{\text {hourly }}$ would significantly increase all-cause and cardiorespiratory mortality risks, with the elderly experienced high vulnerability to TV-related mortality effects. Comparable mortality risks were detected between these two metrics, but greater fractions were appeared using $\mathrm{TV}_{\text {daily }}$ than those using $\mathrm{TV}_{\text {hourly. }}$. Respiratory mortality related to TV exhibited substantially larger fractions than cardiovascular causes. Our findings may add significance to TV-mortality research and help promote optimal health management strategies to better mitigate TV-related health effects. 


\section{Declarations}

\section{Ethics approval and consent to participate}

Not applicable.

\section{Consent to Participate}

Not applicable.

\section{Consent to Publish}

Not applicable.

\section{Author Contributions}

Yong Yu: Software, Writing-review \& editing, Formal analysis, Siqi Luo: Writing - original draft, Writingreview \& editing, Visualization, Yuanyuan Zhang: Methodology, Writing-review \& editing, Data curation, Linjiong Liu: Data curation, Writing-review \& editing, Ke Wang: Writing - review \& editing, Le Hong: Writingreview \& editing, Qun Wang: Conceptualization, Visualization, Data curation, Writing - review \& editing, Supervision, Funding acquisition.

\section{Funding}

This study was supported by Science and Technology Research Project of Hubei Provincial Department of Education (Grant No. Q20201104), Open Fund Project of Hubei Province Key Laboratory of Occupational Hazard Identification and Control (Grant No. OHIC2020Y01).

\section{Competing Interests}

The authors declare they have no competing financial interests.

\section{Availability of data and materials}

Not applicable.

\section{References}

1. Ban J, Xu D, He MZ et al. (2017) The effect of high temperature on cause-specific mortality: A multicounty analysis in China Environ Int 106:19-26 doi:10.1016/j.envint.2017.05.019

2. Bhaskaran K, Gasparrini A, Hajat S et al. (2013) Time series regression studies in environmental epidemiology International journal of epidemiology 42:1187-1195 doi:10.1093/ije/dyt092

3. Chen R, Yin P, Wang L et al. (2018) Association between ambient temperature and mortality risk and burden: time series study in 272 main Chinese cities BMJ 363:k4306 doi:10.1136/bmj.k4306 
4. Cheng J, Xu Z, Bambrick H et al. (2017) The mortality burden of hourly temperature variability in five capital cities, Australia: Time-series and meta-regression analysis Environ Int 109:10-19 doi:10.1016/j.envint.2017.09.012

5. Cheng J, Xu Z, Bambrick H et al. (2019a) Impacts of exposure to ambient temperature on burden of disease: a systematic review of epidemiological evidence Int J Biometeorol 63:1099-1115 doi:10.1007/s00484-019-01716-y

6. Cheng J, Xu Z, Bambrick H et al. (2019b) Impacts of heat, cold, and temperature variability on mortality in Australia, 2000-2009 Sci Total Environ 651:2558-2565 doi:10.1016/j.scitotenv.2018.10.186

7. Gasparrini A (2011) Distributed Lag Linear and Non-Linear Models in R: The Package dlnm Journal of statistical software 43:1-20

8. Gasparrini A, Armstrong B (2013) Reducing and meta-analysing estimates from distributed lag nonlinear models BMC medical research methodology 13:1 doi:10.1186/1471-2288-13-1

9. Gasparrini A, Guo Y, Hashizume M et al. (2015) Mortality risk attributable to high and low ambient temperature: a multicountry observational study The Lancet 386:369-375 doi:10.1016/s01406736(14)62114-0

10. Gasparrini A, Guo Y, Sera F et al. (2017) Projections of temperature-related excess mortality under climate change scenarios The Lancet Planetary Health 1:e360-e367 doi:10.1016/s25425196(17)30156-0

11. Gasparrini A, Leone M (2014) Attributable risk from distributed lag models BMC Med Res Methodol 14:55 doi:10.1186/1471-2288-14-55

12. Graudenz GS, Landgraf RG, Jancar $S$ et al. (2006) The role of allergic rhinitis in nasal responses to sudden temperature changes J Allergy Clin Immunol 118:1126-1132 doi:10.1016/j.jaci.2006.07.005

13. Guo Y, Gasparrini A, Armstrong B et al. (2014) Global variation in the effects of ambient temperature on mortality: a systematic evaluation Epidemiology (Cambridge, Mass) 25:781-789 doi:10.1097/ede.0000000000000165

14. Guo Y, Gasparrini A, Armstrong BG et al. (2016) Temperature Variability and Mortality: A MultiCountry Study Environ Health Perspect 124:1554-1559 doi:10.1289/EHP149

15. Hu K, Guo Y, Yang X et al. (2019) Temperature variability and mortality in rural and urban areas in Zhejiang province, China: An application of a spatiotemporal index Sci Total Environ 647:1044-1051 doi:10.1016/j.scitotenv.2018.08.095

16. Lee JY, Kim H, Gasparrini A et al. (2019) Predicted temperature-increase-induced global health burden and its regional variability Environment international 131:105027 doi:10.1016/j.envint.2019.105027

17. Lee W, Kim Y, Sera F et al. (2020) Projections of excess mortality related to diurnal temperature range under climate change scenarios: a multi-country modelling study The Lancet Planetary Health 4:e512-e521 doi:10.1016/s2542-5196(20)30222-9

18. Li C, Bloom MS, Lin S et al. (2021) Temperature variation and preterm birth among live singleton deliveries in Shenzhen, China: A time-to-event analysis Environ Res 195:110834 
doi:10.1016/j.envres.2021.110834

19. Lim YH, Reid CE, Mann JK et al. (2015) Diurnal temperature range and short-term mortality in large US communities Int J Biometeorol 59:1311-1319 doi:10.1007/s00484-014-0941-2

20. Ma C, Yang J, Nakayama SF et al. (2019) The association between temperature variability and cause-specific mortality: Evidence from 47 Japanese prefectures during 1972-2015 Environ Int 127:125-133 doi:10.1016/j.envint.2019.03.025

21. Martinez-Nicolas A, Meyer M, Hunkler S et al. (2015) Daytime variation in ambient temperature affects skin temperatures and blood pressure: Ambulatory winter/summer comparison in healthy young women Physiol Behav 149:203-211 doi:10.1016/j.physbeh.2015.06.014

22. Peng RD, Dominici F, Pastor-Barriuso R et al. (2005) Seasonal analyses of air pollution and mortality in 100 US cities Am J Epidemiol 161:585-594 doi:10.1093/aje/kwi075

23. Song $X$, Wang $S$, Hu Y et al. (2017) Impact of ambient temperature on morbidity and mortality: An overview of reviews Sci Total Environ 586:241-254 doi:10.1016/j.scitotenv.2017.01.212

24. Vicedo-Cabrera AM, Forsberg B, Tobias A et al. (2016) Associations of Inter- and Intraday Temperature Change With Mortality American journal of epidemiology 183:286-293 doi:10.1093/aje/kwv205

25. Viechtbauer W (2010) Conducting Meta-Analyses inRwith themetaforPackage Journal of Statistical Software 36 doi:10.18637/jss.v036.i03

26. Yang J, Yin P, Zhou M et al. (2015) Cardiovascular mortality risk attributable to ambient temperature in China Heart 101:1966-1972 doi:10.1136/heartjnl-2015-308062

27. Yang J, Zhou M, Li M et al. (2018) Vulnerability to the impact of temperature variability on mortality in 31 major Chinese cities Environ Pollut 239:631-637 doi:10.1016/j.envpol.2018.04.090

28. Yang J, Zhou M, Ren Z et al. (2021) Projecting heat-related excess mortality under climate change scenarios in China Nat Commun 12:1039 doi:10.1038/s41467-021-21305-1

29. Ye X, Wolff R, Yu W et al. (2012) Ambient temperature and morbidity: a review of epidemiological evidence Environ Health Perspect 120:19-28 doi:10.1289/ehp.1003198

30. Zhan Z, Zhao Y, Pang S et al. (2017) Temperature change between neighboring days and mortality in United States: A nationwide study Sci Total Environ 584-585:1152-1161 doi:10.1016/j.scitotenv.2017.01.177

31. Zhan ZY, Tian Q, Chen TT et al. (2020) Temperature Variability and Hospital Admissions for Chronic Obstructive Pulmonary Disease: Analysis of Attributable Disease Burden and Vulnerable Subpopulation Int J Chron Obstruct Pulmon Dis 15:2225-2235 doi:10.2147/copd.S260988

32. Zhang Y, Xiang Q, Yu C et al. (2019a) Mortality risk and burden associated with temperature variability in China, United Kingdom and United States: Comparative analysis of daily and hourly exposure metrics Environ Res 179:108771 doi:10.1016/j.envres.2019.108771

33. Zhang Y, Xiang Q, Yu Y et al. (2019b) Socio-geographic disparity in cardiorespiratory mortality burden attributable to ambient temperature in the United States Environ Sci Pollut Res Int 26:694-705 
doi:10.1007/s11356-018-3653-z

34. Zhang Y, Yu Y, Peng M et al. (2018) Temporal and seasonal variations of mortality burden associated with hourly temperature variability: A nationwide investigation in England and Wales Environ Int 115:325-333 doi:10.1016/j.envint.2018.03.036

35. Zhao Q, Coelho M, Li S et al. (2018) Spatiotemporal and demographic variation in the association between temperature variability and hospitalizations in Brazil during 2000-2015: A nationwide timeseries study Environ Int 120:345-353 doi:10.1016/j.envint.2018.08.021

\section{Figures}

\section{Metropolises in United States}

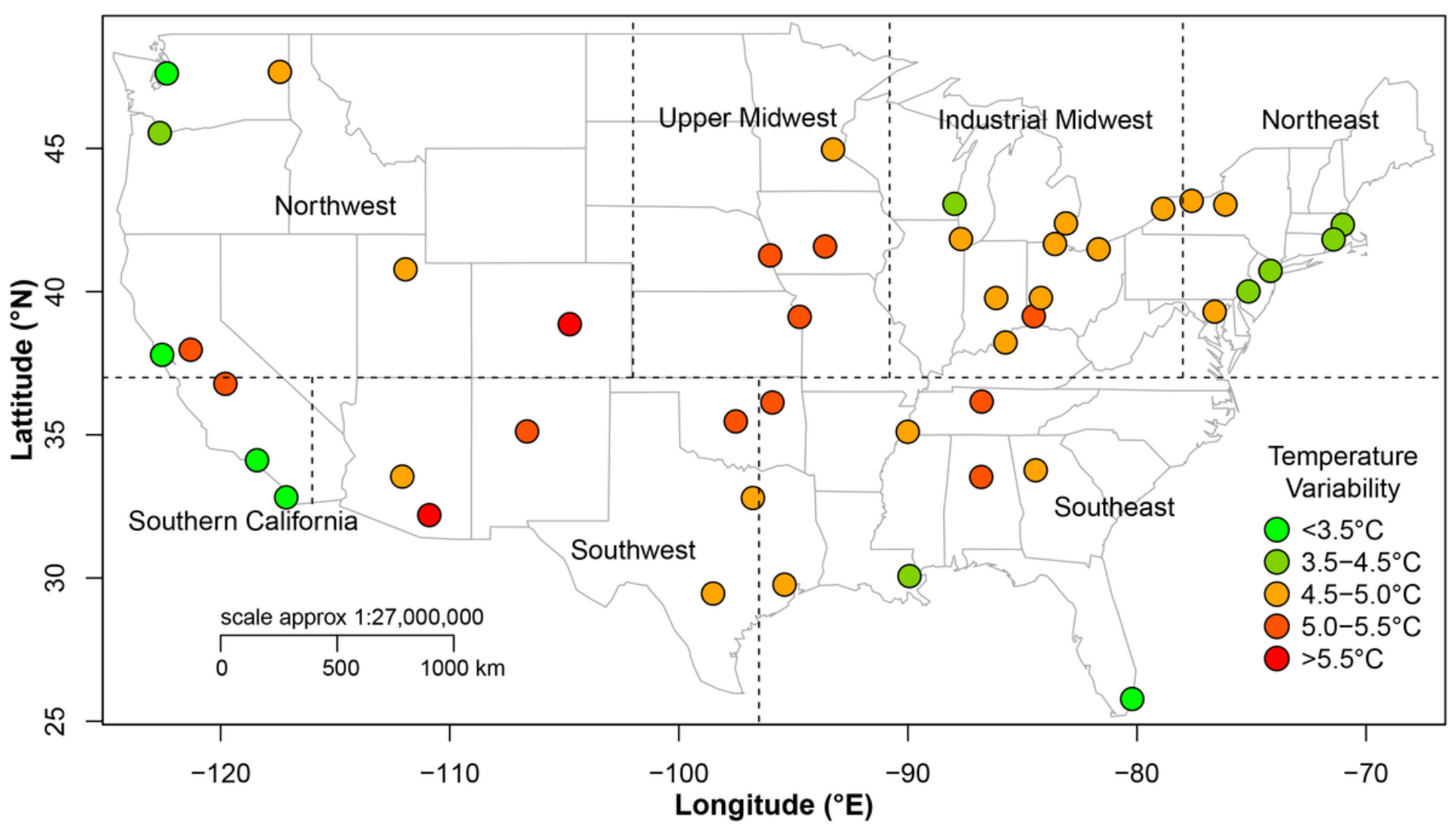

Figure 1

Locations of 45 metropolises in the United States and city-specific hourly temperature variability (7 regions were divided by dotted lines). 


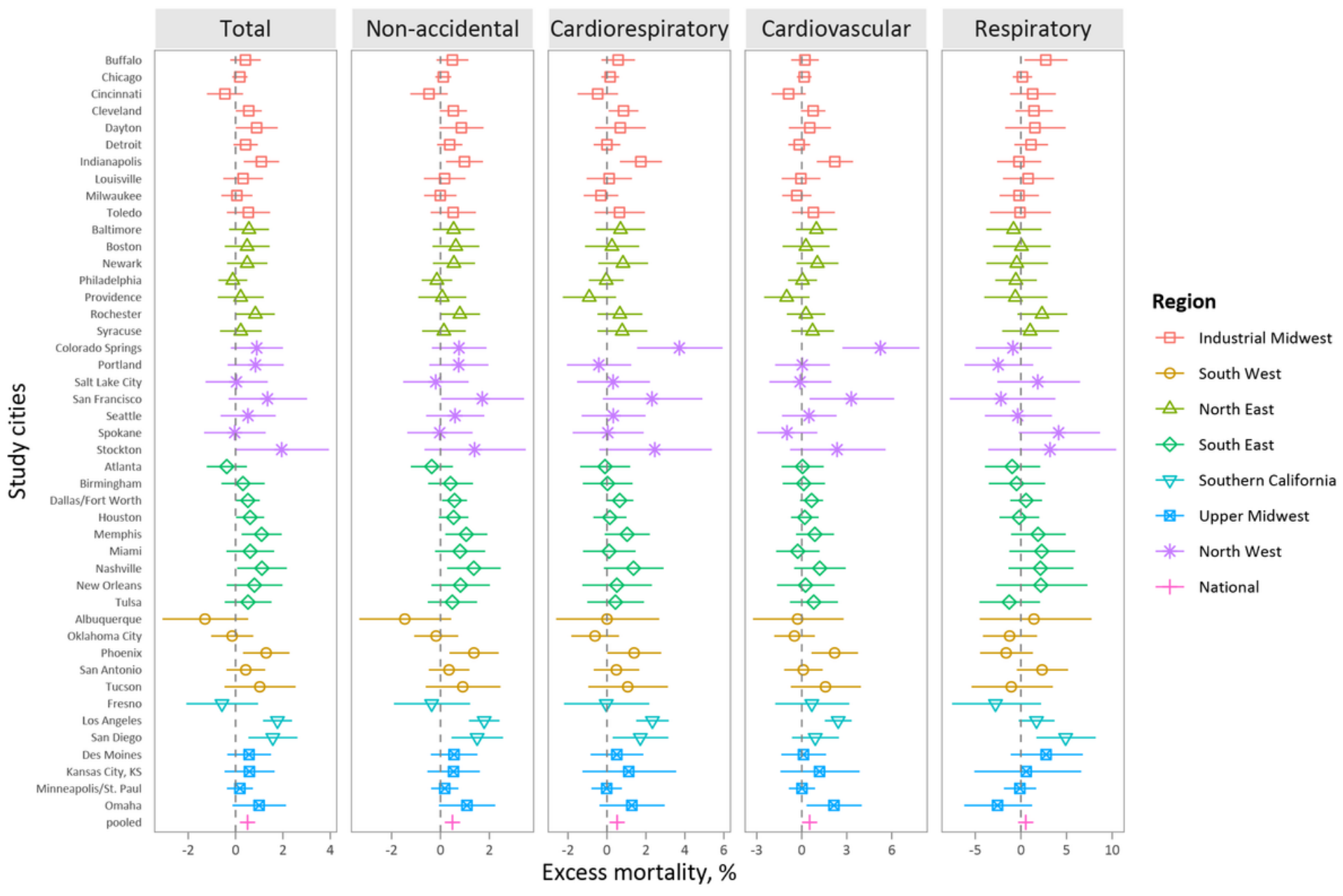

Figure 2

Estimated excess mortality risks due to TVhourly from different mortality categories at lag $0-7$ days on each location. 


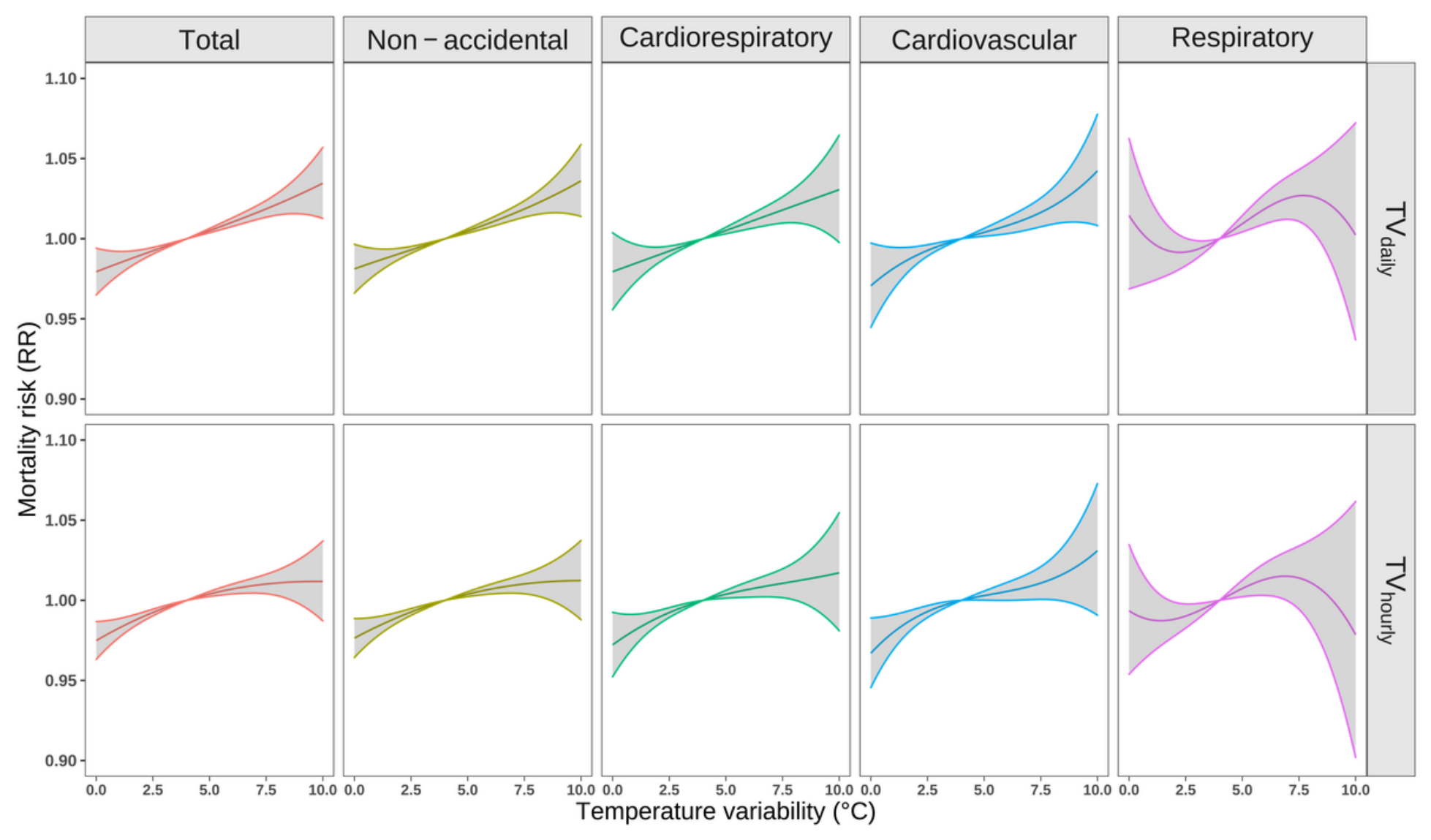

Figure 3

All-cause and cause-specific exposure-response curves (smoothing using natural cubic splines with $\mathrm{df}=$ 3) between TVdaily, TVhourly and mortality. The continuous lines represent the estimated mortality risks and the grey areas are the $95 \%$ confidence intervals. 


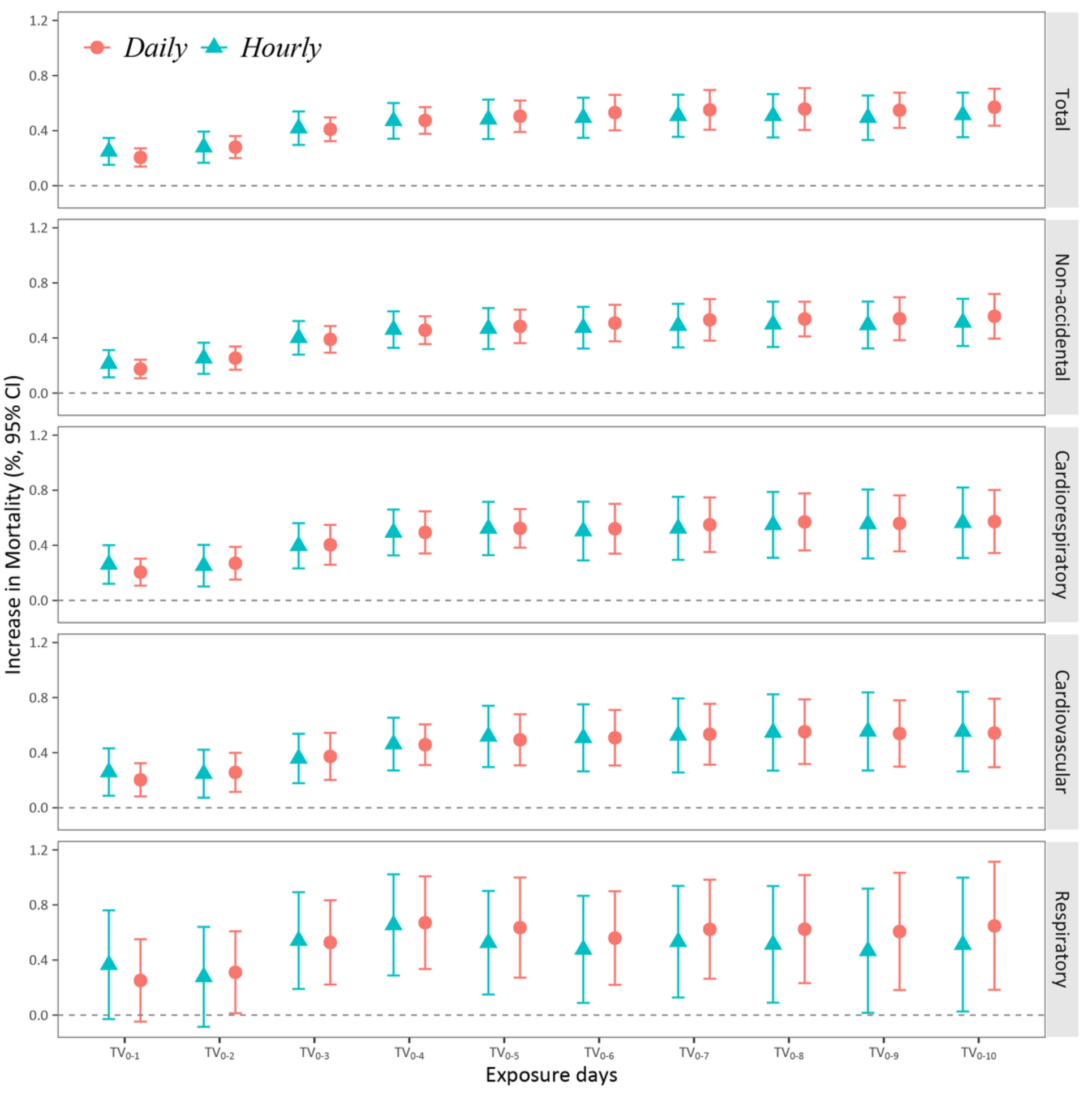

Figure 4

Mortality changes $(\%, 95 \% \mathrm{Cls})$ associated with per $1{ }^{\circ} \mathrm{C}$ increase in TVdaily and TVhourly along various exposure days and different causes of death. The solid dots are the average effect estimates and the error bars represent the $95 \%$ confidence intervals.

\section{Supplementary Files}


This is a list of supplementary files associated with this preprint. Click to download.

- SupplementaryMaterial.docx 